American Journal of Agricultural and Biological Sciences 6 (2): 287-300, 2011

ISSN 1557-4989

(C) 2011 Science Publications

\title{
Evaluation of Soil Moisture Sensors under Intelligent Irrigation Systems for Economical Crops in Arid Regions
}

\author{
Mohamed Said Abdall El Marazky, Fawzi Said Mohammad \\ and Hussein Mohamed Al-Ghobari \\ Department of Agricultural Engineering, College of Food and Agriculture Sciences, \\ King Saud University, Riyadh 11451, Kingdom of Saudi Arabia
}

\begin{abstract}
Problem statement: In irrigation water management, irrigation water use represents a substantial opportunity for agriculture water savings. Automation of irrigation systems, based on Soil Moisture Sensors Systems (SMSS) has the potential to provide maximum water use efficiency by maintaining soil moisture at optimum levels. Approach: The objective of this research was to evaluate the performance of soil moisture sensors under field conditions during growing season in two different irrigated. This evaluation to be conducted with regard to accuracy; precision; quickness of the response to moisture variation. Moreover to quantify the easiness of use, this encompasses installing and operating the instrument as well as interpreting the readings. Results: The Watermark resulted in higher tension readings than the tensiometers. While Watermark showed a consistent and increasingly drier estimate of water content compared to tensiometers. However, the trend of soil water tension curves that resulted from both treatments was very similar. The linear relationships of the Soil Moisture Content (SMC) obtained from all sensors and gravimetric measurement were observed to be best fit. The correlations $\left(\mathrm{R}^{2}\right)$ are ranging from $0.96-0.98$ and from $0.91-0.95$ for tensiometers and watermarks successively. The statistical analyses indicate that changeability existed between soil water contents by the sensors and the gravimetric method. Conclusion: Soil Moisture Sensors Systems (SMSS) can be used: To monitor soil moisture sensors under wheat crop cultivation practices using intelligent irrigation system. The tensiometers and Watermarks were less responsive to the soil drying between irrigations than GM. So, Watermark can operate in a drier range than tensiometers, but with a lower resolution at the wet end of soil water tension. Anyhow, watermark remains a good tool for automatic irrigation scheduling and be integrated with inelegant irrigation systems even the noted drawbacks.
\end{abstract}

Key words: Sensor performance, soil water content sensor, statistical analysis, Soil Moisture Content (SMC), Soil Moisture Sensors Systems (SMSS), intelligent irrigation system, Evapotranspiration (ET), Gravimetric Method (GM), Control Treatment (CT), Relative Root Means Square Error (RRMSE)

\section{INTRODUCTION}

Recent technological advances have made soil water sensors available for efficient and automatic operation of irrigation systems. Sensors for soil moisture monitoring have been used in various natural resource management practices, such as research on crop yield, watershed management, environmental monitoring, precision agriculture and irrigation scheduling. One such application, which forms the focus of this research, is the role of electrical sensors in irrigation scheduling in economical wheat production.
In advanced agriculture, many instruments and methods have been used to monitor and measure soil moisture. Tensiometers, watermarks, resistance blocks, gravimetric methods, granular matrix and Enviroscan sensors have been commonly used for many decades and will continue to be applied in irrigation scheduling (Leib et al., 2002; 2003; McCann and Star, 2007; McCready et al., 2009). Many studies comparing soil moisture sensors with gravimetric method have been reported in the literature. These measurement methods can be classified into direct (gravimetric) and indirect (i.e., soil moisture sensor technologies). However, it is

Corresponding Author: M.S.A. El Marazky, Department of Agricultural Engineering, College of Food and Agricultural Sciences, King Saud University, P.O. Box 2460, Riyadh 11451, Saudi Arabia Tel: + 966568809299 Fax: + 96614678502 
indispensable as a standard method for calibration and evaluation purposes (Walker et al., 2004). A number of scientific studies have described their application to irrigation scheduling (Hanson et al., 2000; Leib et al., 2002;2003; Blonquist et al., 2006; Thompson et al., 2007; Mehdi et al., 2008). Advances in irrigation sciences have made new technology available and increasingly accessible to agricultural producers (Walker et al., 2004; Fisher, 2007). Evapotranspiration (ET) has crucial role in agricultural activity, that maximum and minimum value was estimated by Penman, Penman-Monteith ( $\mathrm{P}$ and $\mathrm{M}$ ) belonging to equation to evaluate general relationships for estimating monthly and daily, respectively (Saghravani et al., 2009). These technologies include Evapotranspiration (ET) based irrigation and soil water sensor based irrigation, sometimes referred to as 'Intelligent technologies' (McCready et al., 2009) that provide irrigation methods based on actual water requirements and crop use taking into account weather factors.

Many researchers have investigated automation of irrigation systems using the soil moisture sensing devices such as tensiometers. Switching tensiometers have been used in various sandy soil applications such as fresh market tomatoes (Smajstrla and Locascio, 1996; Muoz-Carpena et al., 2003), to automatically control irrigation events based on preset soil matric potential limits. Tensiometers have typically been used to initiate and stop a preset timed irrigation event (Torre-Neto et al., 2000; Dukes and Scholberg, 2005).

Watermark sensors are widely available and have a number of favorable technical characteristics for onfarm use, due to its low cost, ease of installation and durability (Thompson et al., 2006). These sensors has been in use for many years and subjected to many calibration efforts and field studies (Thomson et al., 1996; Chow et al., 2009; Shock et al., 2002; Leib et al., 2003; Cardenas-Lailhacar and Dukes, 2010; Fisher, 2007; McCann and Star, 2007). Since the development of the watermark sensors, many researchers have used it in irrigation scheduling. However, in coarser textured soils the contact soil/sensor may reduce and lead to incorrect estimation of soil water tension (Irmak and Haman, 2001; Taber et al., 2002; Thompson et al., 2007). These soil-moisture retention variations reflect textural differences and point to the inherent role of suction in the unsaturated earth materials (Raj, 2010).

Saving water in the agriculture sector through efficient irrigation is one way to reduce water consumption. In today's commercial agriculture, technology plays an important role in different sectors of farm management. This is true particularly in soil moisture sensor technologies which have proven to be efficient in helping corporate growers manage irrigation. The performance of soil moisture sensor systems related to soil water content has been reported (McCready et al., 2009; Zotarelli et al., 2009; Cardenas-Lailhacar and Dukes, 2010). The system performance has been enhanced by use of microcontroller, Circuit design complexity and cost has been reduced and also it's easy to upgrade (Al Smadi, 2011).

Several statistical parameters were used to compare calibrated sensors and Gravimetric Method (GM). The mean difference, $(\mathrm{Md})$, suggested by (Addiscott and Whitmore, 1987) and the Relative Root Mean Square Error, (RRMSE), proposed (Loague and Green, 1991) were used to assess the degree of coincidence between uncelebrated, calibrated and neutron probe water content estimated values. Other statistical analysis methods such as descriptive statistics and t-test were also used to examine the differences between sensor and (GM) measurements (Leib et al., 2003; Jabro et al., 2005).

The objective of this the study was to evaluate the performance of soil moisture sensors under field conditions during growing season in two different irrigated. This evaluation to be conducted with regard to accuracy; precision; quickness of the response to moisture variation. Moreover to quantify the easiness of use, this encompasses installing and operating the instrument as well as interpreting the readings.

\section{MATERIALS AND METHODS}

Site location and sensors installations: This study was performed at the experimental farm of the college of food and Agriculture Sciences, King Saud University, Riyadh. The site was divided into two fields planted with wheat crop one field was irrigated and controlled by Intelligent System (IIS) and the other one field was used as Control Treatment (CT). Intelligent irrigation usually depends on systems utilizing modern electronic sensors which capable of collecting data, analyzing and decision making to start/stop irrigation. An irrigation controller is a device to operate automatic irrigation systems such as lawn sprinklers and drip irrigation systems. Most controllers have a means of setting the frequency of irrigation, the start time and the duration of watering. The goal of using this system is to create enough information for the irrigation zones to water only as much as is required to keep the plants healthy, based on soil and environmental. Intelligent system can be customized by station (or "zone") for specific plant, soil and sprinkler types. So in (IIS) field crop was irrigated automatically, while (CT) was irrigated based on the climate parameters that are used to measure reference evapotranspiration (ETo). 
Am. J. Agri. \& Biol. Sci., 6 (2): 287-300, 2011

Table 1: Abbreviations code for soil moisture sensors in the experimental

\begin{tabular}{lllll}
\hline & Tensiometer & Watermark & \\
Soil depth $(\mathrm{cm})$ & $\begin{array}{l}\text { Intelligent irrigation } \\
\text { system abbreviations }\end{array}$ & $\begin{array}{l}\text { Control treatments } \\
\text { abbreviations }\end{array}$ & $\begin{array}{l}\text { Intelligent } \\
\text { irrigation system }\end{array}$ & $\begin{array}{l}\text { Control } \\
\text { treatments }\end{array}$ \\
\hline 20 & TIIS 20 & TCT 20 & WIIS 20 & WCT 20 \\
30 & TIIS 30 & TCT 30 & WIIS 30 & WCT 30 \\
60 & TIIS 60 & TCT 60 & WIIS 60 & WCT 60 \\
\hline
\end{tabular}

Table 2: Physical properties of different soil layers at the experimental field

\begin{tabular}{|c|c|c|c|c|c|c|c|c|}
\hline \multirow[b]{2}{*}{ Soil depth $(\mathrm{cm})$} & \multicolumn{8}{|c|}{ Particle size distribution (\%) } \\
\hline & Sand & Silt & Clay & Soil texture class & $\begin{array}{l}\text { BD } \\
\text { g.cm }{ }^{-3}\end{array}$ & $\begin{array}{l}\text { PWP } \\
\mathrm{m}^{3} \mathrm{~m}^{-3}\end{array}$ & $\begin{array}{l}\mathrm{FC} \\
\mathrm{m}^{3} \mathrm{~m}^{-3}\end{array}$ & Field location \\
\hline $0-20$ & 78.21 & 8.98 & 12.81 & Sandy loam & 1.65 & 5.13 & 11.94 & \\
\hline $20-30$ & 69.70 & 13.58 & 16.72 & Sandy loam & 1.60 & 12.65 & 23.36 & Controlled \\
\hline $30-60$ & 66.92 & 15.17 & 17.91 & Sandy loam & 1.59 & 13.62 & 24.48 & \\
\hline $0-20$ & 74.81 & 11.77 & 13.42 & Sandy loam & 1.63 & 5.32 & 14.74 & Intelligent system \\
\hline $20-30$ & 72.64 & 11.65 & 15.71 & Sandy loam & 1.62 & 6.54 & 17.27 & \\
\hline $30-60$ & 70.35 & 14.82 & 14.83 & Sandy loam & 1.61 & 6.54 & 15.90 & \\
\hline
\end{tabular}

$\mathrm{BD}=$ Bulk density, $\mathrm{PWP}=$ permanent welting point, $\mathrm{FC}$ = field capacity

These values are then compared with those obtained from the intelligent system in both fields of wheat crop variety (YecoraRojo). Soled sprinkler irrigation system was used for both fields to irrigate wheat crop variety (YecoraRojo). This system was design to ensure a uniform distribution of applied irrigation water to the field and no runoff occurred.

Soil water content must be accurately observed for irrigation decision support. It is applauded by growers and researchers as the world's leading irrigation monitoring and scheduling device. Irrigation scheduling installation a necessary sensors. Theses sensors are capable of interfacing with electrical and automatic controllers to sense soil moisture continuously. Soil water potential was measured by two types, watermark and tensiometer sensors (Watermark model 200ss and tensiometer Irrometer Co., Riverside, CA). The tensiometer and Watermark sensors were positioned at 20, 30 and $60 \mathrm{~cm}$ from soil surface. Moreover, moisture content was measured by the volumetric method at the same depth from the soil surface, which was used for calibration, proposes. In this method, soil samples were taken from fields three times each week and analyzed in the irrigation laboratory. Three of each sensor was placed in each field then; they are calibrated and configured to implement the next phase of the study before collecting real data (Table 1). All sensors were read daily at 8:00 A.M. from Saturday through Wednesday at the same times of taking soil samples for gravimetric method. Soil potentials measured by tensiometers and watermarks for Intelligent Irrigation System (IIS) and Control Treatments (CT) fields throughout the growing season are plotted versus days since crop planting. The volumetric soil water content determined from the soil samples was regressed against the sensors probe and gopher readings. Regression equations transforming the sensors probe reading to volumetric water content were developed. These equations were used for calibration all the soil moisture measuring devices used in this study.

Soil analyses and data collection: Before starting the experiment, soil samples were taken from different locations to determine the mechanical soil analysis for the two fields (Table 2). Locations were selected such that they represent the dominant soil conditions in the fields. Three samples were taken from each field at three different depths $(20,30,60 \mathrm{~cm})$ to determine the soil properties. At two locations across the study site, soil samples were collected from each soil horizon to develop a soil water retention curve. Soil water content at tensions ranging from $0-15 \mathrm{kPa}$ was determined for each sample. The relationship between matric potential and volumetric water content in a soil is termed as soil moisture characteristic curve. The tensiometers and watermark sensors readings were in tension units, centibars and $\mathrm{KPa}$, respectively.

These reading had to be converted to volumetric water content readings using soil moisture characteristic curves for corresponding each soil layer. Curves were used to convert tension readings to volumetric water content data. This conversion was necessary to make the comparison with the gravimetric method. The total samples collected from the gravimetric method were 36 during sensors three times a week.

Statistical analysis: Several statistical parameters were used to compare the calibrated sensors and gravimetric method. Three statistical parameters were adopted to assess the performance of each sensor against GM. The mean difference $(\mathrm{Md})$, which describes the average difference between sensors data and the corresponding GM measurements were used to assess the degree of coincidence between this mean difference was given as: 
$\mathrm{Md}=\frac{\sum_{\mathrm{i}=1}^{\mathrm{n}}\left(\mathrm{M}_{\mathrm{si}}-\mathrm{M}_{\mathrm{gi}}\right)}{\mathrm{n}}$

Md is taken as the average value of each week. The values of soil moisture data throughout the season extended for a period of 12 weeks. Where $M_{s i}$ and $M_{g i}$ are measurement obtained by a sensor and gravimetric method respectively and $\mathrm{n}$ are the numbers of samples. The Relative Root Means Square Error (RRMSE) proposed and calculated as follows:

$\operatorname{RRMSE}=\left\lceil\frac{1}{\mathrm{n}} \sum_{\mathrm{i}=1}^{\mathrm{n}}\left(\mathrm{M}_{\mathrm{si}}-\mathrm{M}_{\mathrm{gi}}\right)^{2}\right\rceil^{0.5} \times \frac{(100)}{\mathrm{Mg}}$

where, $\mathrm{Mg}$ is the corresponding mean of gravimetric measurement, calculated as:

$\mathrm{M}_{\mathrm{g}}=\frac{1}{\mathrm{n}} \sum_{\mathrm{i}=1}^{\mathrm{n}} \mathrm{M}_{\mathrm{gi}}$

The coefficient of determination ( $r 2$ ) was used to display the degree of similarity between sensors and GM measurements. This analysis is using the slope and intercept of the linear regression between the sensor and GM measurements. If the sensors performed well, the value of the Md and RRMSE should be close to zero, with a significant linear regression indicated by an intercept of zero at slope 1 and $r 2$ of 1 . Other statistical analysis method such as t-test was used to examine the differences between calibrated sensors and the GM measured values.

\section{RESULTS}

Soil water status: The soil analyses show that the dominant soil textures of the layers (0-20, 20-30, 30-60 $\mathrm{cm})$ are sandy loam. Results of soil water potentials measured by tensiometers during the season for intelligent and control irrigation treatments of wheat crop are presented in Fig. 1-2. Pattern of curves in Fig. 1 are similar to those shown in Fig. 2 except the potentials in Fig. 2 are little higher. The practical operating potential range of tensiometer is from 10-70 $\mathrm{KPa}$ (Fig. 1). The soil water potential readings by tensiometers were ranged from 10-60, 12-60 and 14-70 for the layers $0-20,20-30$ and $30-60 \mathrm{~cm}$, respectively.

Figure 1a shows that the soil water potential verses time for intelligent irrigation system. This figure indicates that the values of soil moisture tension in the second and third layers were less than $50 \mathrm{KPa}$ during early 30 days. While, the tension values for the third layers were less than $50 \mathrm{KPa}$ first 16 days from beginning the season only.

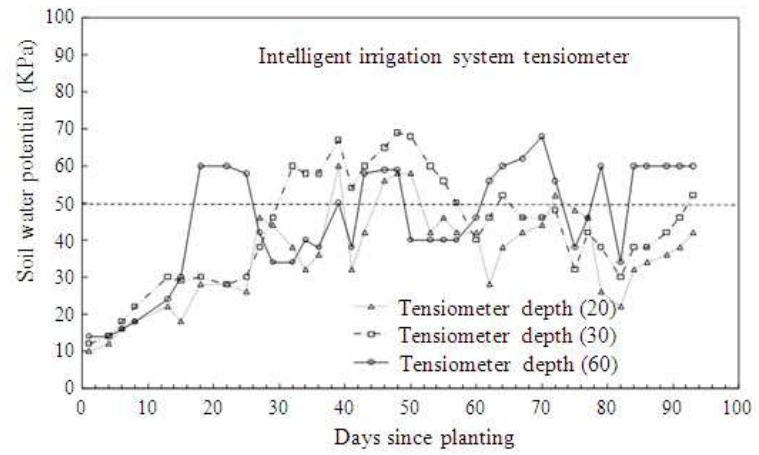

(a)

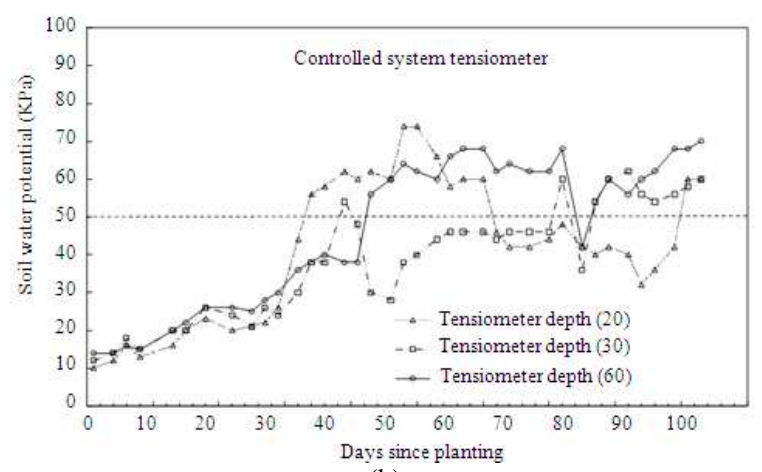

(b)

Fig. 1: Daily Soil water potential measured by tensiometers for (a) intelligent and (b) controlled irrigation treatments

While it can be noticed in the same figure that tension values for the three layers are fluctuating starting from 30th day. Generally, tensiometer reading showed that the tension values are ranging from 10-70 $\mathrm{KPa}$ during the enter season (Fig. 1a). In control treatment the tension by tensiometer followed almost similar trend of that tension in intelligent system (Fig. 1b). This figure shows clearly the values of tension for three layers were less than $50 \mathrm{KPa}$ an early 322 days. Noting that the fluctuation tension values are ranging from 26-62 $\mathrm{KPa}$ for period of 30-90 days after cultivation (Fig. 1b). Generally, watermark reading showed that the tension values are ranging from 10-75 $\mathrm{KPa}$ during the enter season (Fig. 1b). Hence, it can be seen that the watermark less sensitive at soil water tension lower than $22 \mathrm{kPa}$. It is clear from Fig. 2 that the accuracy of watermark sensor when is the tension up to $22-90 \mathrm{kPa}$.

Figure $2 \mathrm{a}$ shows that the soil water potential by watermark verses time for intelligent system. The value of tension of the two layers 20 and $60 \mathrm{~cm}$ were less than $50 \mathrm{KPa}$ for a period of 32 days from the beginning of the season. While in the second layer, 30 $\mathrm{cm}$ was less than $50 \mathrm{KPa}$ for a short only a period equal to 12 days from the beginning of the season. 


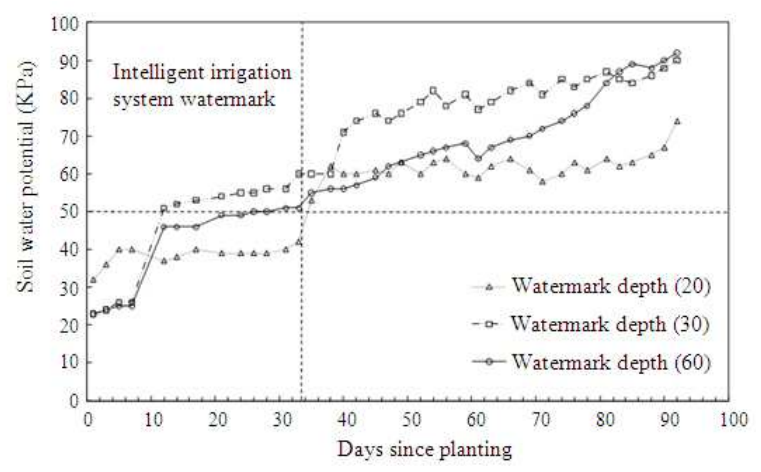

(a)

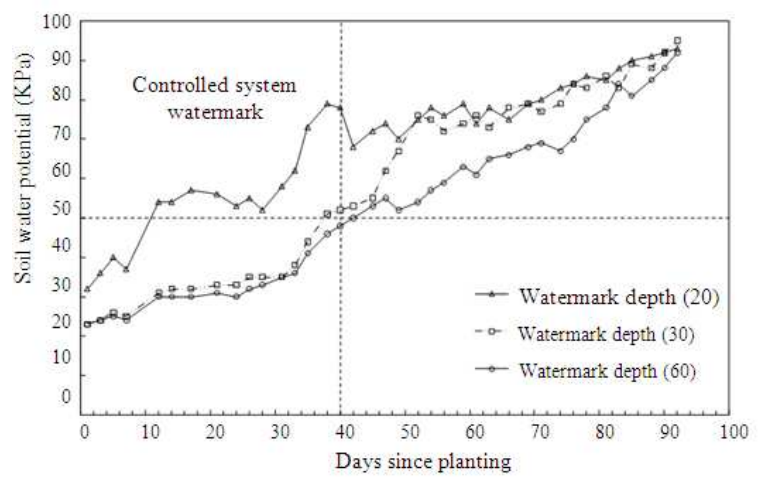

(b)

Fig. 2: Daily Soil water potential measured by watermark for (a) intelligent and (b) controlled irrigation treatments

Similar trend was noticed for tension values of watermarks except the congestion of the three layers values near to the end of the sensor (Fig. 2 b).It is also can be noted same figure that soil tensions for the three layer are greater than $50 \mathrm{KPa}$ for a period started from 30-90 days. As can be seen in the (Fig. 1-2) of the soil water potential derived indices, on occasions there was notable variation between treatment values from individual SWC probes. However, given the similarity in general tendencies and fluctuations that we observed between sensors at different depths and between replicate probes.

The volumetric soil water content determined from the samples is regressed against the tensiometers and watermark readings (Fig. 3-4). The regression equation transforming the potential readings to volumetric Soil Water Content (SWC) are generated as shown in both figures. The tensiometers and Watermarks were less responsive to the soil drying between irrigations than gravimetric method. This trigger was based on soil sample analysis conducted at the $0-60 \mathrm{~cm}$ depths at all hub sites. Most of the sensors covered this depth and furthermore the root zone of most crops was located at this depth.

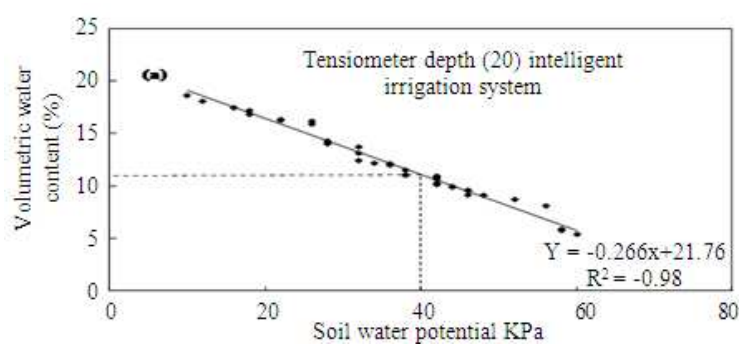

(a)

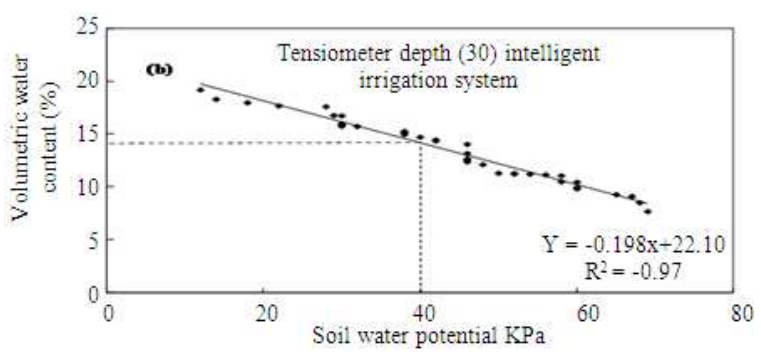

(b)

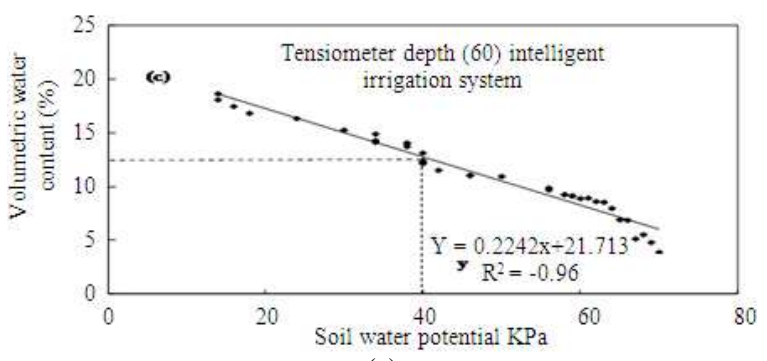

(c)

Fig. 3: Soil water potential by tensiometers regressed against soil moisture content by gravimetric method for intelligent system for the three layers

From the experiments conducted on wheat crop, calibration equations for sensors and treatments, the readings were obtained using a liner equation (Figs. 34). The average curves for the watermark and tensiometers are shown in (Fig. 3-4). It can be seen that the curves for both sensors are followed similar trend, but tension values are different. From these figures the soil tension curves are ranging from 10-90 KPa. The volumetric soil water content for three depths shown in this figures is approximately equal to $20 \mathrm{~cm}^{3} / \mathrm{cm}^{3}$ at tension of $10 \mathrm{KPa}$. While for watermark the tensions values 22-32 $\mathrm{KPa}$ are higher than those values of tensiometers.

The tensiometers performed well in the 7-18\% range of volumetric water content (Fig. 3). The tensiometers did not give measurements lower than $10 \mathrm{Kpa}$ (Fig. 3a), which corresponds to approximately $18 \%$ of volumetric water content. 


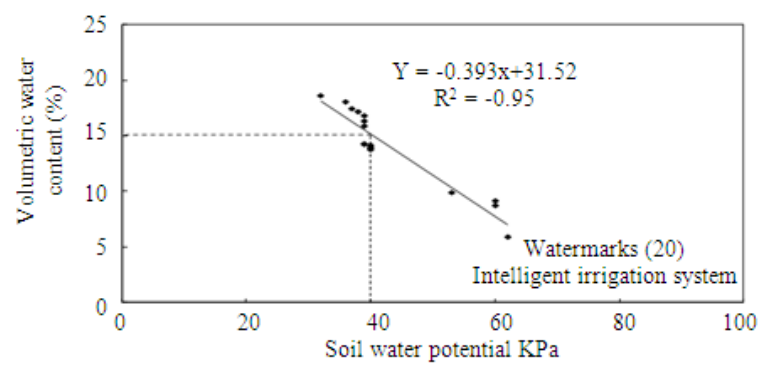

(a)

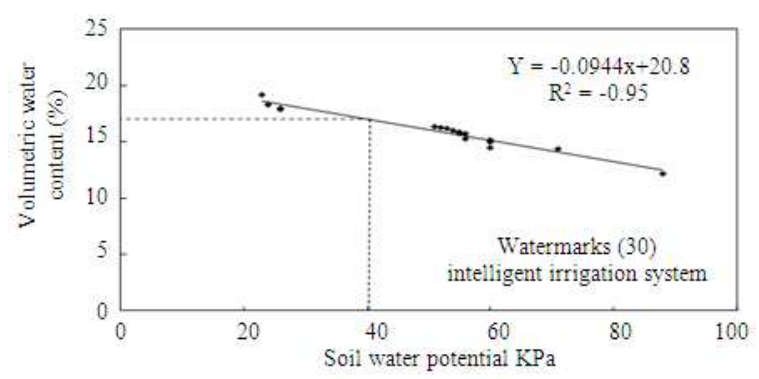

(b)

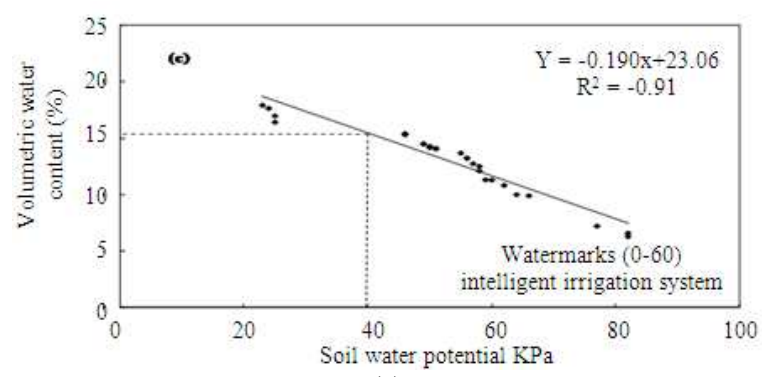

(c)

Fig. 4: Soil water potential by watermark regressed against soil moisture content by gravimetric method for intelligent system for the three layers

On the other side, the maximum measurements were 70 $\mathrm{Kpa}$, of which corresponds to approximately $8 \%$ of volumetric water content (Fig. 3b). It should be noted that the tensiometer readings remained at $40 \mathrm{KPa}$ when the volumetric water content ranged from 12-14\% (Fig. $3 \mathrm{a}-\mathrm{c})$. The watermark performed well in the 9-19\% range of volumetric water content (Fig. 3). The watermark did not give measurements lower than $30 \mathrm{Kpa}$ (Fig. 4a), which corresponds to approximately $18 \%$ of volumetric water content. On the other side, the maximum measurements were $90 \mathrm{Kpa}$, of which corresponds to approximately $12 \%$ of volumetric water content (Fig. 4b). It should be noted that the tensiometer readings remained at $40 \mathrm{KPa}$ when the volumetric water content ranged from $15-17 \%$ (Fig. 4a-c). The tensiometer was found to be reliable only in the 30-50 $\mathrm{KPa}$ rang. Meanwhile, the watermark was found to be reliable only in the 50-65 $\mathrm{KPa}$ rang.

Volumetric water content verses soil potential: The volumetric water content $(\Theta)$ readings were plotted versus matric potential for various sensors (Fig. 5). The differences between measurements from both systems at depths 0-20, 0-30 and 0-60 cm were compared. This figure shows an equivalent volumetric water contents as measured by the various soil moisture sensors at various depths at discrete times. Moreover, (Fig. 5) is revealed that soil moisture content did not yield a smooth variation with soil depth.

It is clear from Fig. 5a and $b$ that the values of $(\Theta)$ ranged from $14-28 \%$ and 15 to $27 \%$ for tensiometers in both treatments, While it is clear from Fig. $5 \mathrm{c}$ and $\mathrm{d}$ that the values of $(\Theta)$ ranged from $10-28 \%$ and $22-27 \%$ for watermarks in both treatments

Soil water retention: To evaluate the performance of soil moisture sensors the soil water retention are measured in the soil laboratory. The soil water content readings were plotted versus matric potential for various different layers in soil profile (Fig. 6).This figure has been used to develop relationships to derive the approximate soil moisture retention curve at corresponding layers. Moreover, the measured energy status of soil water was afterward converted into water contents by volume using the localized retention curve. The soil water content values ranged from 6 , 13 and $15 \%$ for layers 20, 30 and $60 \mathrm{~cm}$ respectively at constant soil matric potential $15 \mathrm{KPa}$, as shown in Fig. 6a-c.

Moreover, corresponding layers as it is noticed from (Fig. 6) variation in soil water content at soil water potential among the layers. These curves are sensitive to the changes in bulk densities and disturbances of soil structures.

Statistical analysis: It was still possible to get a general comparison performance among different sensor types. Hence, demonstrating the variability of accuracy of each sensor when applied with different installation configurations. In comparison between intelligent and control treatments the tensiometer resulted $\mathrm{R}^{2}$ ranged from $92-96 \%$ respectively (Table 4 ). As shown in this table, slopes were ranging from 0.979-1.042 and ranging from 0.835-1.041 in control treatment case. Tensiometer at depth of $30 \mathrm{~cm}$ (TCT 30) had significantly different from zero at $5 \%$ probability level. 


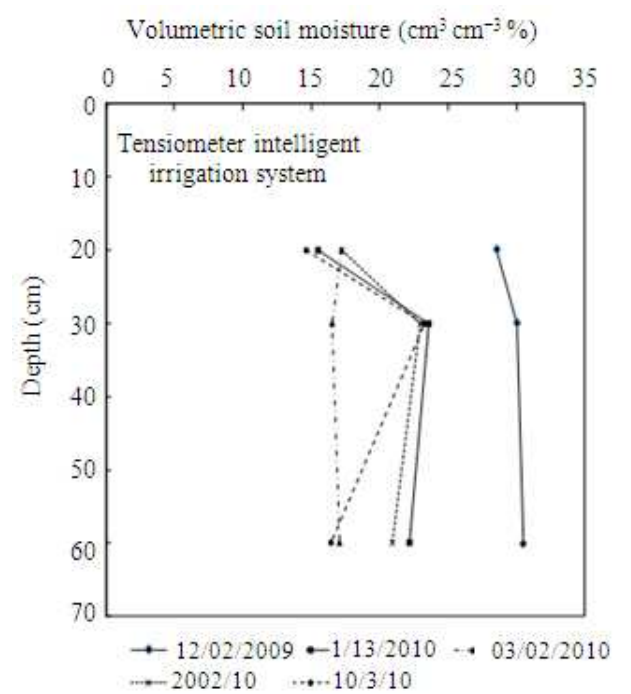

(a)

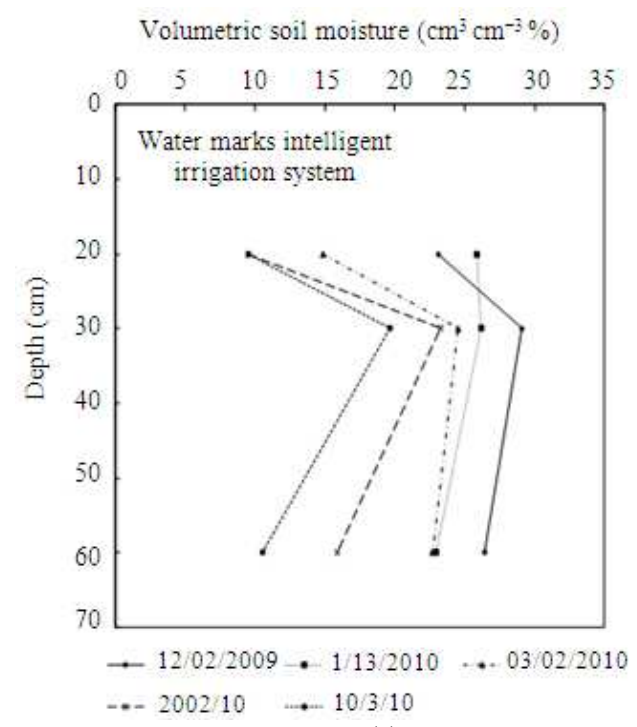

(c)

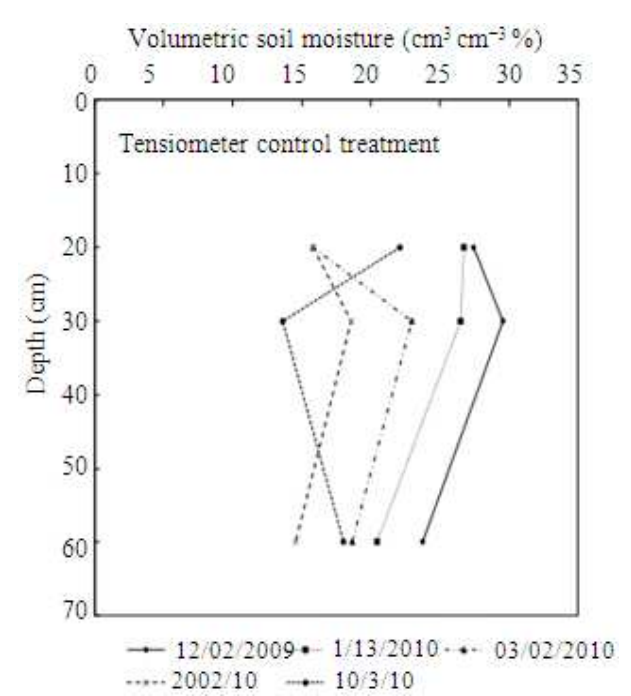

(b)

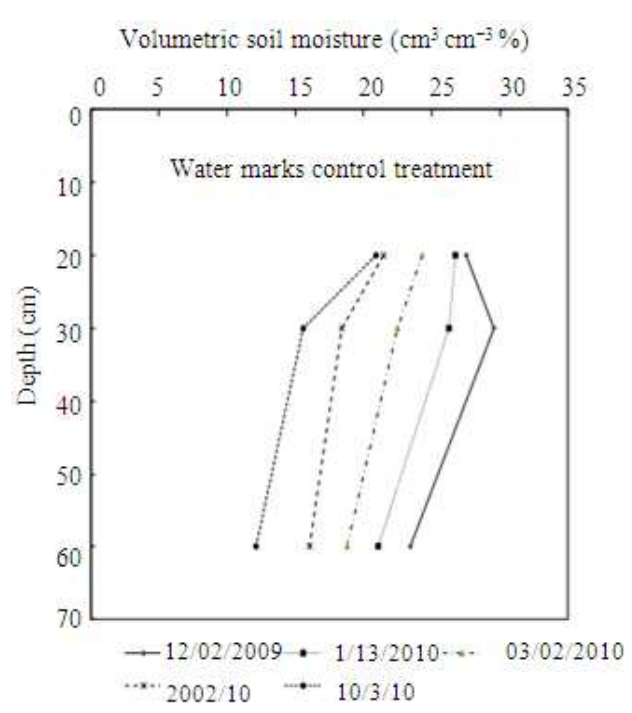

(d)

Fig. 5: Volumetric soil moisture content verses depth for intelligent system and control treatment measurement for various dates

From Fig. 7 can depicted that the tensiometers in all cassis except TIIS 20 and TCT 30 are described as high performance with $\mathrm{R}^{2}=0.96$ and slope 1.041.The scattered dots followed 1:1 line well, in particular, (TIIS 20 and TCT 30) with a nice and tight distribution along the same line (Fig. 7 a and d. It is obvious from Fig. 8 that Watermark data scattered above the 1:1 line which suggests an underestimation of watermark values $(\mathrm{p}<0.0001)$.

Results were plotted on 1:1 line and displayed in Fig. 7-8 for wheat crop, to compare and assess both sensors accuracy calibrated by comparison with those of GM (Table 3). It is clears from the table that results of SMC values are varied not significantly between sensor values and GM measurements. The mean difference values for tensiometers under control irrigation treatments and water contents were small, negative and significantly different from zero $\left(\mathrm{Md}=-0.140 \mathrm{~m}^{3} \mathrm{~m}^{-3} ; \mathrm{t}=-1.005 ; \mathrm{p}<0.336\right)$. However, the Md values $\left(\mathrm{Md}=-1.260 \mathrm{~m}^{3} / \mathrm{m}^{3} ; \mathrm{t}=-\right.$ 8.171 ) for tensiometer under intelligent treatments, were very small and not significantly different from zero (Table 3). 
Am. J. Agri. \& Biol. Sci., 6 (2): 287-300, 2011

Table 3: Statistical analysis for both treatments at three depths

\begin{tabular}{lllllll}
\hline System & Sensors & $\mathrm{N}^{[a]}$ & $\mathrm{Md}$ & Std Err & $\mathrm{T}$ value & Pr> $(\mathrm{t})$ \\
\hline Intelligent irrigation & TIIS 20 & 12 & -0.414 & 0.163 & -2.531 & 0.028 \\
& TIIS 30 & 12 & -0.556 & 0.166 & -3.351 & 0.006 \\
& TIIS 60 & 12 & -1.260 & 0.154 & -8.171 & 0.004 \\
& WIIS 20 & 12 & -1.215 & 0.169 & -7.188 & 0.003 \\
& WIIS 30 & 12 & -1.840 & 0.105 & -17.548 & $0 . .001$ \\
& WIIS 60 & 12 & -1.716 & 0.228 & -7.528 & $0 . .003$ \\
Controlled irrigation & TCT 20 & 12 & -1.141 & 0.184 & -6.214 & 0.002 \\
& TCT 30 & 12 & -0.140 & $0.139^{\mathrm{b}}$ & -1.005 & $<0.336$ \\
& TCT 60 & 12 & -0.793 & 0.088 & -9.009 & 0.004 \\
& WCT 20 & 12 & -1.374 & 0.146 & -9.409 & 0.004 \\
& WCT 30 & 12 & -1.458 & 0.190 & -7.659 & 0.003 \\
& WCT 60 & 12 & -1.694 & 0.137 & -12.399 & 0.002 \\
\hline
\end{tabular}

(a) Number of observations,(b) Significantly different from zero at 5\% probability level,(Std) Standard Error Means

Table 4: RRMSE, Re (\%) and $\mathrm{R}^{2}$ for studied cases

\begin{tabular}{|c|c|c|c|c|c|c|c|}
\hline System & Sensors & $\mathrm{N}^{[\mathrm{a}]}$ & RRMSE & Intercept & Slope & $\operatorname{Re}(\%)$ & $\mathrm{R}^{2}$ \\
\hline \multirow[t]{6}{*}{ Intelligent irrigation } & TIIS 20 & 12 & 6.319 & $0.651^{\mathrm{b}}$ & 0.979 & -3.309 & 0.96 \\
\hline & TIIS 30 & 12 & 6.916 & 0.045 & 1.042 & -4.308 & 0.94 \\
\hline & TIIS 60 & 12 & 13.573 & $1.157^{\mathrm{b}}$ & 1.012 & -10.920 & 0.94 \\
\hline & WIIS 20 & 12 & 10.549 & $2.787^{\mathrm{b}}$ & $0.879^{c}$ & -8.559 & 0.94 \\
\hline & WIIS 30 & 12 & 11.341 & $3.162^{\mathrm{b}}$ & $0.911^{\mathrm{c}}$ & -11.068 & 0.95 \\
\hline & WIIS 60 & 12 & 13.221 & $0.297^{\mathrm{b}}$ & $1.105^{\mathrm{c}}$ & -11.288 & 0.91 \\
\hline \multirow[t]{6}{*}{ Controlled irrigation } & TCT 20 & 12 & 11.645 & $1.274^{\mathrm{b}}$ & 0.985 & -8.717 & 0.92 \\
\hline & TCT 30 & 12 & 4.758 & $-0.425^{\mathrm{b}}$ & 1.041 & -0.958 & 0.96 \\
\hline & TCT 60 & 12 & 9.598 & $2.609^{\mathrm{b}}$ & $0.835^{\mathrm{c}}$ & -7.233 & 0.90 \\
\hline & WCT 20 & 12 & 8.553 & $3.459^{\mathrm{b}}$ & $0.859^{c}$ & -8.500 & 0.94 \\
\hline & WCT 30 & 12 & 8.876 & $5.616^{\mathrm{b}}$ & $0.726^{\mathrm{c}}$ & -8.777 & 0.96 \\
\hline & WCT 60 & 12 & 11.569 & $2.667^{\mathrm{b}}$ & $0.923^{\mathrm{c}}$ & -11.889 & 0.95 \\
\hline
\end{tabular}

(a) Number of observations,(b) Significantly different from zero at 5\% probability level,@ Significantly different from 1 at $5 \%$ probability level,(Re) Relative bias, calculated as (Sensor mean-GM mean)/GM mean $\times 100$

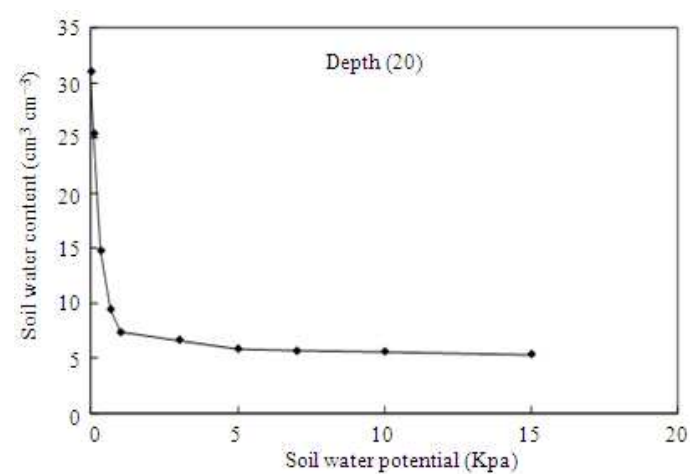

(a)

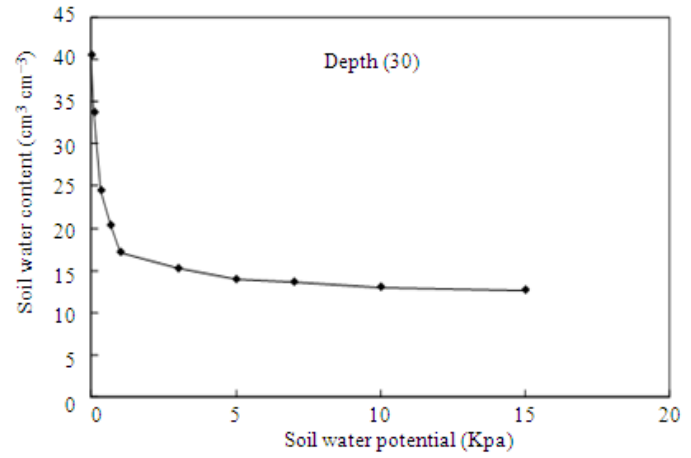

(b)

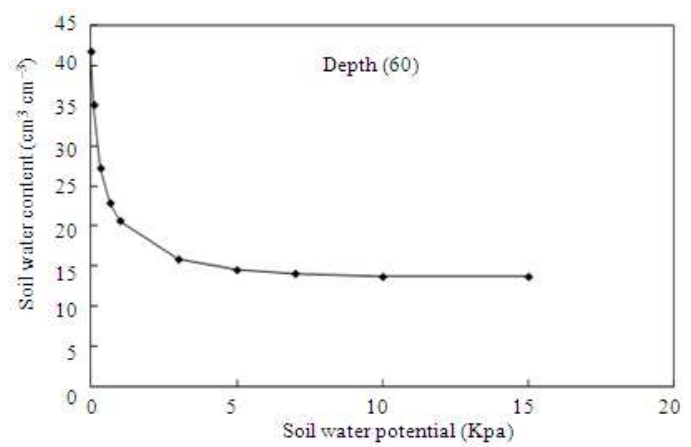

(c)

Fig. 6: Soil water retention characteristic curves for different soil layers 


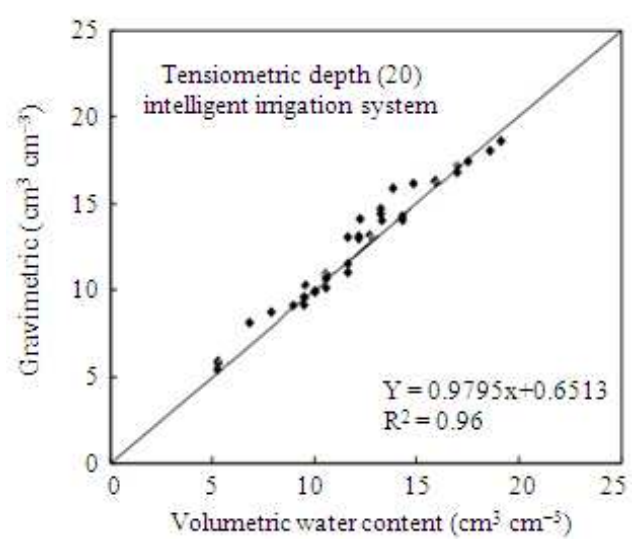

(a)

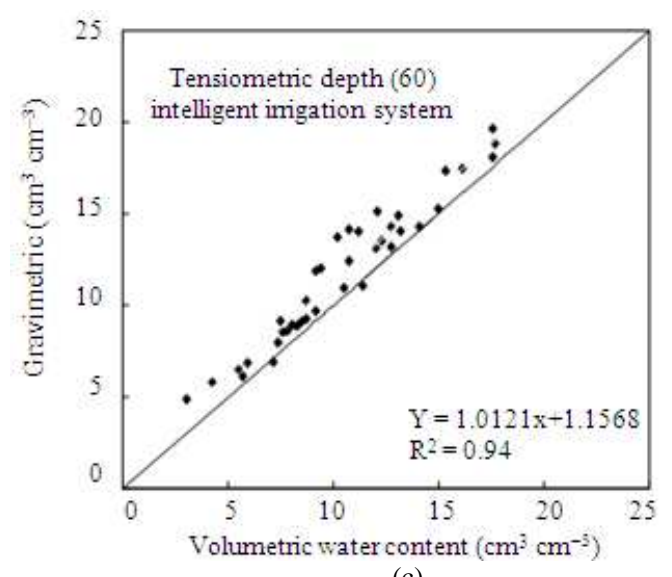

(c)

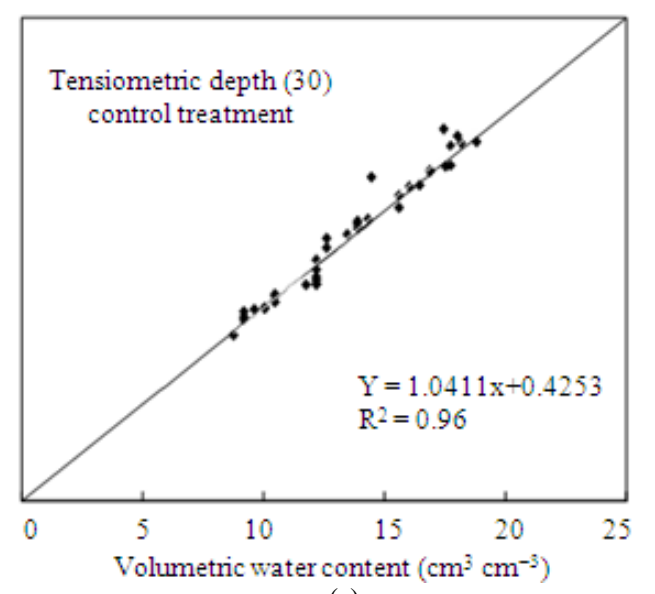

(e)

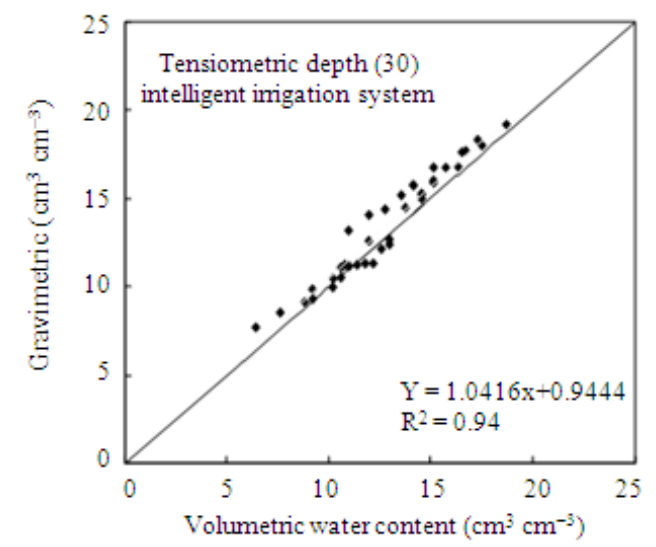

(b)

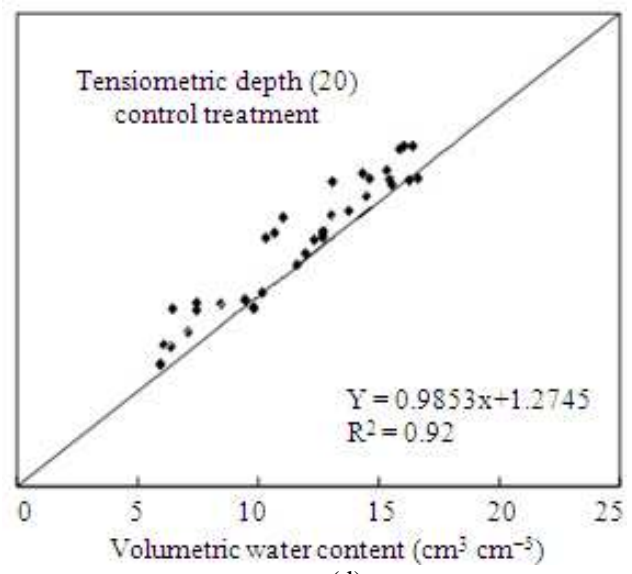

(d)

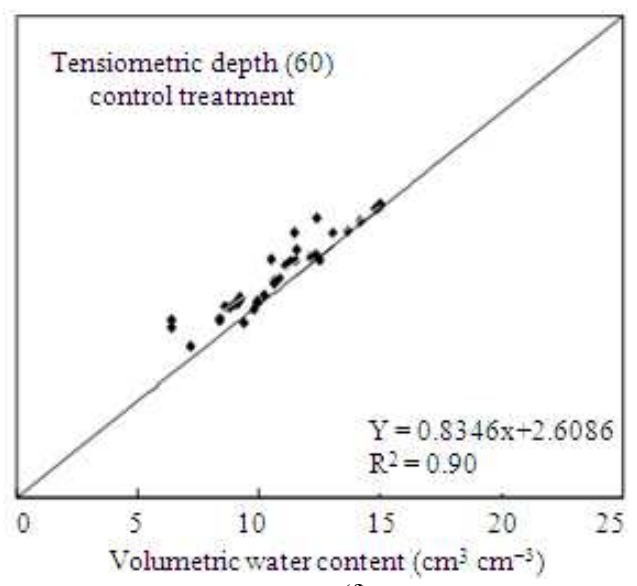

(f)

Fig. 7: Regression relations between gravimetric measurements ( $\mathrm{Y}$ axis) and volumetric water content obtained by tensiometer for both treatments

Statistically, tensiometers were also found to perform the best among the tested sensors according to regression analysis $\left(\mathrm{R}^{2}=0.96\right.$, slope $=0.979 ;$ TS 20) with a Md of-0.140 and smallest RRMSE (Table 4). 
Am. J. Agri. \& Biol. Sci., 6 (2): 287-300, 2011

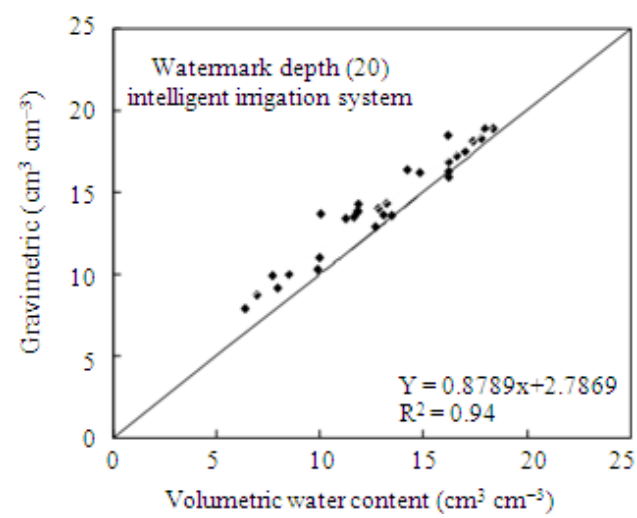

(a)

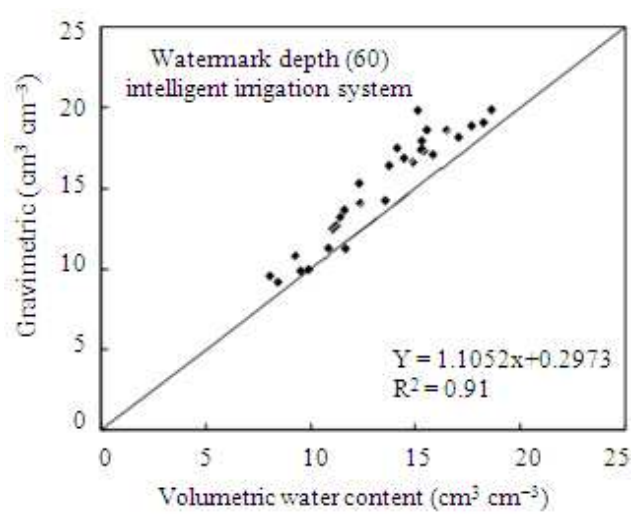

(c)

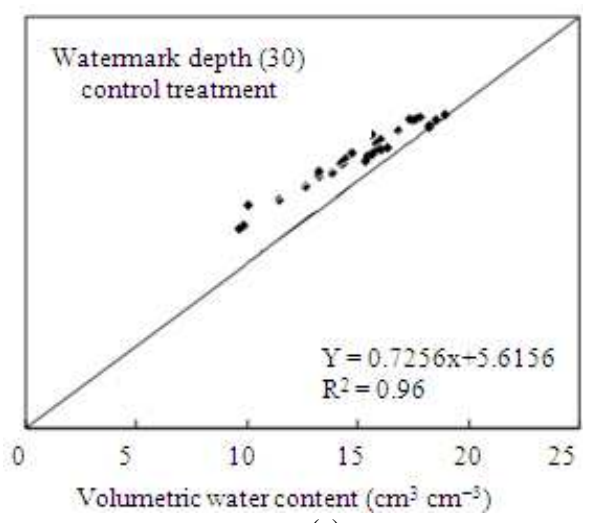

(e)

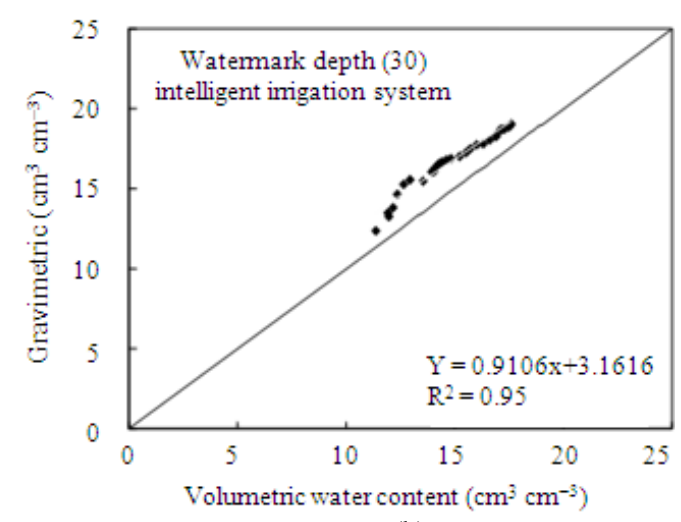

(b)

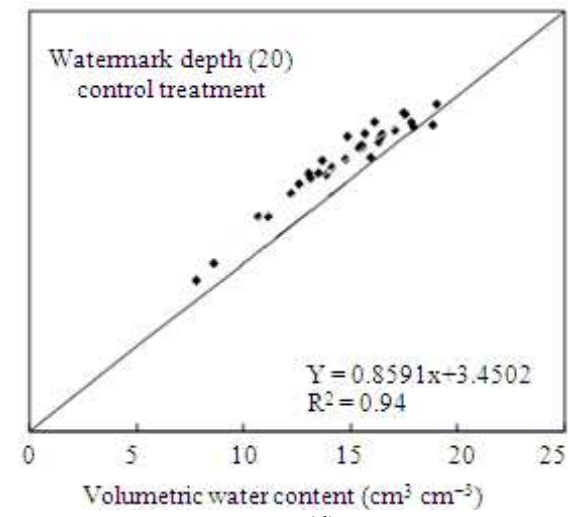

(d)

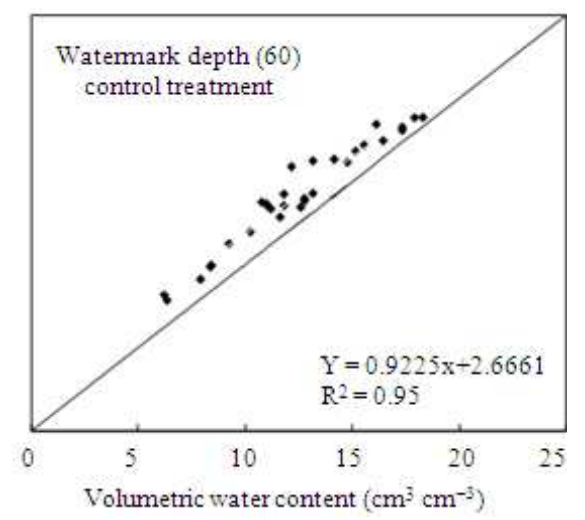

(f)

Fig. 8: Regression relations between gravimetric measurements ( $\mathrm{Y}$ axis) and volumetric water content obtained by watermark for both treatments

Furthermore, RRMSE values of SMC produced from sensors (specially from the third- layers, TIIS 60, WIIS 60 and WCT 60) were very high compared to RRMSE of the sensors in first and second layers, 0-20 and 0-30 $\mathrm{cm}$ (Table 4). This reflects a large distribution scatter in the data.
The RRMSE suggested that the individual value of SMC resulting from the calibration for GM was much more accurate than that estimated by using the soil moisture sensors. Tensiometers performed reasonably well in all three soil layers. Furthermore, Table 4 shows that watermark slightly is poorer than tensiometers and 
could not consistently capture the correct pattern of $\mathrm{SMC}$, in particular, in the $60 \mathrm{~cm}$ layers. The measurements obtained by the TCT 30 under control treatment displayed a very small discrepancy with the GM measurements at same depth and $\mathrm{Re} \%$ is relative bias of only $-0.958 \%$ (Re; Table 4$)$.

The smallest $\mathrm{Md} \mathrm{(-0.140)}$ is not significantly different from 0 (Table 3 ) and the smallest RRMSE is $6.319 \%$ (Table 4). Watermark performed slightly poorer than tensiometer (WCT 60, WIIS 60 and WIIS 30) and displayed a very high discrepancy with the GM measurements at same depths and $\mathrm{Re} \%$ is relative bias for (-11.889, -11.288 and -11.068-Table 4) respectively.

As indicated in Table 4, most sensors performed reasonably well between 20 and $30 \mathrm{~cm}$ depths, which is probably the major targeted soil layer of sensor design. The poorer performances of the tested sensors are may be attributed to large variations of SMC.

\section{DISCUSSION}

Since irrigation in both each treatment by Intelligent System (IIS) and the other one field was used as Control Treatment (CT) was initiated at different time, the data from each treatment was presented and discussed. The data were analyzed to evaluate: (1) evaluate sensor performance over time; (2) evaluate sensor performance under two (treatments) irrigation types; and (3) compare sensor measurement errors over all variables and over time. To evaluate these points, the data analyzed graphically (e. g., Fig. 1 through 8). The soil water potentials for intelligent and control irrigation treatments, based on Soil Moisture Sensors Systems (SMSS) has the potential to provide maximum water use efficiency by maintaining soil moisture at optimum levels. This is in line with the amount of irrigation water, which was added to the control treatment, which is often more than that water added by intelligent irrigation system. For the intelligent irrigation system the suggested protocols for interpreting these data to identify lower irrigation limits (Fig. 1). Watermark less sensitive at soil water tension, this is could be due to electrical resistance of watermark is affected by status of saturation and dray conditions. Hence, the Watermark may not be a suitable tool in those cases where irrigation practices maintain a low soil water tension. Watermark has a hysteretic behavior when induced to rapid drying or partial rewetting of the soil, which could affect the performance of the Watermark in estimating the actual soil water status (Fig. 2).

The soil water potential between sensors at different depths and between replicate probes. There was notable variation between treatment values from individual SWC probes. In open field situations, the overall rate of soil drying may be faster with larger daily extraction values. At tensions below this value, tensiometers resulted in lower tension than the watermark. Both sensing methods followed a similar trend, but specific tension readings were different. In spite of all these limitations, Watermark may be useful when a relative indication of soil wetness is needed. Therefore,_Watermark can be operated in a drier range domain than tensiometers, but with a lower resolution at wet end. This is an important limitation for the use of Watermark in the predominantly coarse-textured soils. These results obtained agree with (Hanson et al., 2000; Irmak and Haman, 2001; Leib et al., 2001; Intrigliolo and Castel, 2004). Generally, soil sensors overly different from each other, mainly when the soil type is sand. Despite Watermark and tensiometer following the major pattern of soil water content and being low cost to purchase they did perform satisfactorily in this region. Increasing the number of duplications and careful and frequent calibration could possibly make these methods more acceptable (Leib et al., 2003; Irmak and Haman, 2001) if continuous measurements must be made. Finally, it is important to remember that in the soil moisture sensor-experiment, due to favorable weather conditions.

The soil water tension curves were very similar between all different replications. Therefore, tensiometers and watermark remains a good tool for automatic irrigation scheduling and be integrated with inelegant irrigation systems. The performance of those sensors was, therefore, directly dependent on the accuracy of the soil moisture characteristic curve. Both the tensiometers and watermark sensor followed for a narrow range of water contents. Each type had its own narrow range of water contents where the readings were close to the actual water content (Fig. 3-4).

The inter comparison of the two treatments shows that $(\Theta)$ under controlled treatment continually gave higher than that for intelligent irrigation system. The non-smooth variation of Soil Moisture Content (SMC) with depth for both sensors may be as a result of physical differences in soil property with depth. It is noticed that there is no regular trend for water distribution in the soil profile. Generally, the moisture content is higher in lower layers than the upper ones. This is due to the first layer is susceptible to more evaporation than the other layers (Fig. 5). In general, this indicates the values of $(\Theta)$ are almost close to each other with some variation for both sensors. The minor differences could be due to the manner of water infiltration process. Therefore, it is difficult to withdraw a solid conclusion because there are no significant differences between all cases. Hence, it is clear from 
this analysis the differences in values of $(\Theta)$ are due to interaction of many factors such as, an installation procedure for the sensors, theories variations behind each sensor and air or fluid filled gaps surrounding sensors (Fig. 5).

It is an evident that the values of tension moisture in three layers under study have not shown a significant difference and almost are equal. It is clear the differences among soil moisture characteristic curves are attributed primarily to the differences in pore size distribution among soils (Fig. 6).

Generally, both sensors followed the major trend of soil water content at different depths and reflected the impacts of irrigation pattern over time. However, each sensor behaved differently at different soil depths, in particular, after irrigation. Overall, the trends in SMC results demonstrate the variability of accuracy of each sensor when applied over different soil layers with different installation configurations. This is because of vertical variations of soil texture and water conditions. Furthermore, the distribution range of watermark measurements was significantly smaller than GM data and showed a good performance, except for the last few data points. From inter-comparisons it is safe to conclude that soil moisture sensors performed differently with different soil depths. Climate and soil physical conditions may be additional factors which directly or indirectly influence the sensitivity of sensors. This can significantly influence soil water measurements, in particular, measured by resistance sensors (Watermark). Therefore, most of these sensors are successfully able to produce accurate trend variations in soil moisture content values over a period of time following irrigation events. As indicated the Gopher achieved the highest $r^{2}$ and very high slope in regression analysis in this test, the scatter plot showed a reasonably high range pattern which could significantly bias the method in terms of the time series, suggesting a calibration issue.

\section{CONCLUSION}

The research carried out in this study was to monitor soil moisture sensors under wheat crop cultivation practices using intelligent irrigation system. Soled sprinkler irrigation systems used to irrigate wheat crop via Intelligent and Control treatments were monitored. Two types of soil sensors used in this study to measure the soil-water potential are, Tensiometers and Watermark. Three gropes for each sensors were installed in three plots of sandy loam soil at a depth of 20, 40, $60 \mathrm{~cm}$ from the soil surface. Hence, demonstrating the variability of accuracy of each sensor when applied with different installation configurations. A set of soil moisture content measurements by three methods (Tensiometers, Watermarks, Gravimetric) were taken from plots, treatments once each week. Volumetric water content $(\Theta)$ was used as a unit of reference for the purpose of comparing sensors.

The tensiometers and Watermarks were less responsive to the soil drying between irrigations than GM. So, Watermark can operate in a drier range than tensiometers, but with a lower resolution at the wet end of soil water tension. Anyhow, watermark remains a good tool for automatic irrigation scheduling and be integrated with inelegant irrigation systems even the noted drawbacks. Calibration equations for both sensors and treatments, the readings were obtained using a liner equation. The curves for both sensors are followed similar trend, but tension values are different. The inter comparison shows that $(\Theta)$ under controlled treatment continually gave higher than that for intelligent irrigation system. The values of tension moisture in three layers under study have not shown a significant difference and almost are equal.

The statistical analysis also supports considerable discrepancies between soil water contents estimated by the site-calibration Gravimetric and sensors readings. The mean difference, Md and the relative root mean square error; RRMSE was used to assess the degree of coincidence. An Md value equal to zero denotes no difference between these measurements. A smaller RRMSE indicates better performance. The correlations $\left(\mathrm{R}^{2}\right)$ are ranging from $0.96-0.98$ and from $0.91-0.95$ for tensiometers and watermarks successively. Tensiometer at depth of $20-30 \mathrm{~cm}$ (TCT 30) had significantly different from zero at $5 \%$ probability level. A watermark measurement was significantly smaller than GM data and showed a good performance, except for the last few data points.

The smallest $\mathrm{Md}(-0.140)$ is not significantly different from 0 and the smallest RRMSE is $6.319 \%$. Watermark performed slightly poorer than tensiometer (WCT 60, WIIS 60 and WIIS 30) and displayed a very high discrepancy with the GM measurements at same depths and $\operatorname{Re} \%$ is relative bias for $(-11.889,-11.288$ and -11.068) respectively. Most sensors performed reasonably well between 20 and $30 \mathrm{~cm}$ depths, therefore, these sensors are successfully able to produce accurate trend variations in SMC values over a period of time following irrigation events. Therefore, sitespecific calibration is essential for the most precise soil moisture content measurements as well as to improve the sensor's accuracy and performance. 


\section{ACKNOWLEDGMENT}

The researchers wish to thank The National Plan for Science and Technology (King Saud University in cooperation with King Abdul-Aziz City for sciences and Technology) for providing funds to undertake this study through Grant No. 08-WAT 327-2.

\section{REFERENCES}

Addiscott, T.M. and A.P. Whitmore, 1987. Computer simulation of changes in soil mineral nitrogen and crop nitrogen during autumn, winter and spring. J. Agric. Sci., 109: 141-157. DOI: 10.1017/S0021859600081089

Al Smadi, T.A., 2011. Low cost smart sensor design. Am. J. Eng. Applied Sci., 4: 162-168. DOI: 10.3844/ajeassp.2011.162.168

Blonquist, J.M., S.B. Jones and D.A. Robinson, 2006. Precise irrigation scheduling for turfgrass using a subsurface electromagnetic soil moisture sensor. Agric. Water Manage., 84: 153-165. DOI: 10.1016/J.AGWAT.2006.01.014

Cardenas-Lailhacar, B. and M.D. Dukes, 2010. Precision of soil moisture sensor irrigation controllers under field conditions. Agric. Water Manage., 97: 666-672. DOI: 10.1016/J.AGWAT.2009.12.009

Chow, L., Z. Xing, H.W. Rees, F. Meng and J. Monteith et al., 2009. Field performance of nine soil water content sensors on a sandy loam soil in new brunswick, maritime region, Canada. Sensors, 9: 9398-9413. DOI: $10.3390 / \mathrm{s} 91109398$

Dukes, M. D. and J.M. Scholberg, 2005. Soil moisture controlled subsurface drip irrigation on sandy soils. Applied Eng. Agric., 21: 89-101. http://asae.frymulti.com/abstract.asp?aid=17916\&t $=1$

Fisher, D.K., 2007. Automated collection of soilmoisture data with a low-cost microcontroller circuit. Applied Eng. Agric., 23: 493-500. http://ddr.nal.usda.gov/handle/10113/17622

Hanson, B.R., S. Orloff and D. Peters, 2000. Monitoring soil moisture helps refine irrigation management. Calif. Agric., 54: 38-42. http://www.cabdirect.org/abstracts/20001916075.html

Intrigliolo, D.S. and J.R. Castel, 2004. Continuous measurement of plant and soil water status for irrigation scheduling in plum. Irrig. Sci., 23: 93-102. DOI: 10.1007/s00271-004-0097-7

Irmak, S. and D.Z. Haman, 2001. Performance of the WaterMark Granular matrix sensor in sandy soils. Applied Eng. Agric., 17: 787-795. http://asae.frymulti.com/abstract.asp?aid=6848\&t= 1
Jabro, J.D., B.G. Leib and A.D. Jabro, 2005. Estimating soil water content using site-specific calibration of capacitance measurements from Enviroscan system. Applied Eng. Agric., 21: 393-399. http://asae.frymulti.com/abstract.asp?aid=18458\&t $=1$

Leib, B.G., J. Jay, D. Matthews and R. Gary, 2003. Field evaluation and performance comparison of soil moisture sensors. J. Soil Sci., 168: 396-408. http://cat.inist.fr/?aModele $=$ afficheN\&cpsidt $=1490$ 9979

Leib, B.G., M. Hattendorf, T. Elliott and G. Mattews, 2002. Adoption and adaptation of scientific irrigation scheduling: Trends from Washington, USA as of 1998. Agric. Water Manage., 55: 105120. DOI: 10.1016/S0378-3774(01)00191-3

Loague, K. and R.E. Green, 1991. Statistical and graphical methods for evaluating solute transport models: Overview and application. J. Contam. Hydrol., 7: 51-73. DOI: 10.1016/01697722(91)90038-3

McCann, I.R. and J.L. Star, 2007. Field evaluation of dual frequency multi-sensor capacitance probes for water and nutrient management in drip irrigation. Am. Soc. Agric. Biol. Eng. http://asae.frymulti.com/abstract.asp?aid=22982\&t $=1$

McCready, M.S., M.D. Dukes and G.L. Miller, 2009. Water conservation potential of Intelligent irrigation controllers on St. Augustinegrass. Agric. Water Manage, 96: 1623-1632. http://econpapers.repec.org/article/eeeagiwat/v_3a9 6_3ay_3a2009_3ai_3a11_3ap_3a1623-1632.htm

Mehdi, B., C.A. Madramootoo, A. Gollamudi, S. Ali and A. Verhallen et al., 2008. A comparison of soil moisture monitoring technologies for irrigation scheduling. Proceedings of the ASABE Annual International Meeting, Rhode Island Convention Center. Jun. 29-July 2, Providence, Rhode Island. http://asae.frymulti.com/abstract.asp?aid=24639\&t $=2$

Muoz-Carpena, R.., H. Bryan, W. Klassen, T.T. Dispenza and M.D. Dukes, 2003. Evaluation of an automatic soil moisture-based drip irrigation system for row tomatoes. Proceedings of the ASABE Annual International Meeting, July 27-30. Las Vegas, Nevada, USA. http://asae.frymulti.com/abstract.asp?aid=14944\&t $=1$

Raj, J.K., 2010. Soil-moisture retention characteristics of earth materials in the weathering profile over a porphyritic biotite granite. Am. J. Geosci., 1: 12-20. http://citeseerx.ist.psu.edu/viewdoc/download?doi=1 0.1.1.20.1272\&rep=rep1\&type $=$ pdf 
Saghravani, S.R., S. Mustapha, S. Ibrahim and E. Randjbaran, 2009. Comparison of daily and monthly results of three evapotranspiration models in tropical zone: A case study. Am. J. Environ. Sci., 5: 698-705. DOI: 10.3844/ajessp.2009.698.705

Shock, C.C., E.B.G. Feibert, L.D. Saunders and E.P. Eldredge, 2002. Automation of subsurface drip irrigation for crop research. Proceedings of the World Congress of Computers in Agriculture and Natural Resources, Mar. 13-15, Iguacu Falls, Brazil, pp: 809-816. http://asae.frymulti.com/abstract.asp?aid=8415\&t= 1

Smajstrla, A.G. and S.J. Locascio, 1996. Tensiometercontrolled, drip scheduling of tomato. Applied Eng. Agric., 12: 315-319. http://asae.frymulti.com/abstract.asp?aid=25654\&t $=1$

Taber, H.G., V. Lawson, B. Smith and D. Shogren, 2002. Scheduling microirrigation with tensiometers or Watermarks. Int. Water Irrig., 22: 22-26. http://md1.csa.com/partners/viewrecord.php?reque ster $=$ gs \& collection $=$ TRD $\&$ recid $=0607033 \mathrm{EN} \& \mathrm{q}=$ \&uid=790833102\&setcookie $=$ yes

Thompson, R.B., M. Gallardo and M.D. Fernande, 2007. Using plant water status to define threshold values for irrigation management of vegetable crops using soil moisture sensors. Agric. Water Manage., $\quad 88$ : 147-158. DOI: 10.1016/J.AGWAT.2006.10.007
Thompson, R.B., M. Gallardo, T. Aguera, L.C. Valdez and M.D. Fernande, 2006. Evaluation of the watermark sensor for use with drip irrigated vegetable crops. Irrig. Sci., 24: 185-202. DOI: 10.1007/s00271-005-0009-5

Thomson, S.J., T. Youmos and K. Wood, 1996. Evaluation of calibration equations and application methods for the Watermark granular matrix soil moisture sensor. Applied Eng. Agric., 12: 99-103. http://asae.frymulti.com/abstract.asp?aid=25444\&t $=1$

Torre-Neto, A., J.K. Schueller and D.Z. Haman, 2000. Networked Sensing and Valve Actuation for Spatially-Variable Microsprinkler Irrigation. St. Joseph, Mich, ASAE. http://www.cabdirect.org/abstracts/20003019089.ht $\mathrm{ml}$

Walker, J.P., G.R. Willgoose and J.D. Kalma, 2004. In situ measurement of soil moisture: A comparison of techniques. J. Hydrol., 293: 85-99. DOI: 10.1016/J.JHYDROL.2004.01.008

Zotarelli, L., J.M. Scholberg, M.D. Dukes, R. MunozCarpena and J. Icerman, 2009. Tomato yield, biomass accumulation, root distribution and irrigation water use efficiency on a sandy soil, as affected by nitrogen rate and irrigation scheduling. Agric. Water Manage., 96: 23-34. DOI: 10.1016/J.AGWAT.2008.06.007 